\title{
A New Type of Control Method for Variable Pitch Wind Turbines
}

\author{
Li Tai \\ School of Electrical Engineering \\ Southeast University \\ Nanjing, China \\ e-mail: teilytl@163.com \\ Lin He-Yun \\ School of Electrical Engineering \\ Southeast University \\ Nanjing, China \\ e-mail: 185441638@qq.com \\ Zhao Li \\ Shan Dong Water Polytechnic \\ Rizhao, China \\ e-mail:zhaoli_20090909@126.com
}

\author{
Hou Xiao-Yan \\ School of Electronic\& Information \\ Jiangsu University of Science and Technology \\ Zhenjiang, China \\ e-mail: bestmytl@126.com \\ Zhu Zhi-Yu \\ School of Electronic\& Information \\ Jiangsu University of Science and Technology \\ Zhenjiang, China \\ e-mail: 1181501030@qq.com \\ Liu Hai-Jian \\ School of Electronic\& Information \\ Jiangsu University of Science and Technology \\ Zhenjiang, China \\ e-mail: 746811429@qq.com
}

\begin{abstract}
When the wind speed is above the rated value, the traditional control strategy is variable pitch control, and the control method is PI control. However, variable pitch wind turbines have strong nonlinear characteristics due to the natural wind which random changes with time and space. For the pitch angle control agencies in the large wind turbines, the bp neural network controller is designed and the controller of the FPGA-based hardware problem is discussed. The analysis of the neural network controller features reconstructed is presented by its three major reconfiguration units. The controller can be established based on the SG/Simulink. The simulation results show that the FPGA-based neural network controller can keep the constant output of wind turbine power, the working efficiency of the variable pitch servo system is improved, and a better idea is provided for the hardware implementation of the neural network in the wind energy conversion system.
\end{abstract}

Keywords- ANN; reconfigurable; PI control; pitch angle; wind turbine

\section{INTRODUCTION}

The energy provided by wind has been gradually increased. Since the 1990 s last century, the global wind power industry has developed rapidly ${ }^{[1]}$, wind energy has been gradually applied to many fields, for example, irrigation, navigation, grinding, city power supply. There are many maximum power point tracking (MPPT) control methods for maximizing the power ${ }^{[2]}$. However, these methods still have shortcomings.

Neural network control technology is widely used because of its advantages in dealing with nonlinear and uncertain, and RBF network is gradually applied to the field of wind power control ${ }^{[3-5]}$. The bp neural network is one of ann's common control method. It is often difficult to establish an accurate plant model in industry, a unique choice is provided by the bp neural network control to deal with the unknown dynamic of nonlinear systems, and it has provided an effective solution to solve maximum power point tracking problems.

Model of wind turbine based on DFIG is built in this paper, and the blade pitch angle controller for the wind turbine is designed, the controller with 1-3-1 BP neural network and the reconfiguration of the neural network are analyzed, the research results are given by the platform of the control system for wind turbine based on FPGA.

\section{Blade Pitch ANGLE Controller With NeURAL NETWORK}

\section{A. Model of DFIG-based Wind Turbines}

As is shown in the Fig .1, structure for DFIG-Based 
wind turbine include wind wheel, gear box, wind generator, AC/DC convertor, grid, etc ${ }^{[6-9]}$.

$$
\begin{gathered}
P_{w t}=\frac{1}{2} r p R^{2} v^{3} C_{p}(l, b) \\
\mathrm{G}_{w t}=\frac{1}{2} r p R^{3} v^{2} C_{\mathrm{G}}(l, b) \\
C_{p}(l, b)=l C_{\mathrm{G}}(l, b) \\
l=\frac{R \mathrm{gW}_{l}}{v}
\end{gathered}
$$

Where, $P_{w t}$ is power of wind wheel, $\mathrm{G}_{w t}$ is torque of wind wheel, $C_{\mathrm{G}}$ is torque coefficient, $l$ is tip speed ratio, $b$ is blade pitch angle, $R$ is radius of wind wheel, $r$ is density of air, $v$ is wind speed.

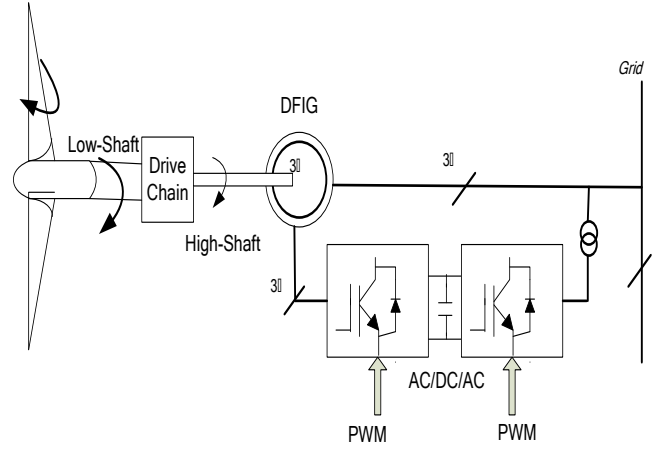

Figure 1. Structure for DFIG-Based Wind Turbine

Model of DFIG generator can be expressed as equation(5):

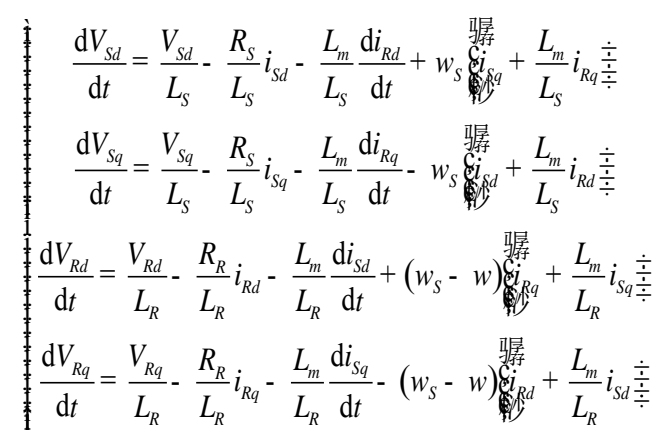

Where, $i_{S d}$ is the stator current of q-axis, $i_{S q}$ is the stator current of d-axis, $i_{R d}$ is rotor current of q-axis, $i_{R q}$ is rotor current of d-axis. $V_{S d}$ is the stator voltage of d-axis, $V_{S q}$ is the stator voltage of q-axis, $V_{R d}$ is the rotor voltage of d-axis, $V_{R q}$ is the rotor voltage of q-axis. $L_{S}$ is the stator inductance, $L_{R}$ is the rotor inductance, $L_{m}$ is mutual inductance of stator and rotor. $R_{S}$ is rotor resistance, $R_{R}$ is stator resistance. $w_{S}$ is synchronous speed of stator, $w=n_{p} \mathrm{~W}_{h}$ is electric angular velocity of rotor, $n_{p}$ is motor pole pairs, $\mathrm{W}_{h}$ is rotor speed.

\section{B. Neural Network Controller}

Reconfigurability is defined as that computing system can use reusable hardware resources at the hardware level, according to different application requirements, the architecture of which can be flexiblely changed. Reconfigurability of BP neural network includes structure reconfigurability and learning algorithm reconfigurability. BP network algorithm design is divided into three main steps:

\section{Forward propagation:}

The input layer of BP network can be expressed as:

$$
\begin{aligned}
& w_{i j}^{k}=\left[\begin{array}{cccc}
w^{k}{ }_{11} & w_{12}^{k} & \ldots & w_{1 N}^{k} \\
w_{21}^{k} & w_{22}^{k} & \ldots & w^{k}{ }_{2 N} \\
\mathrm{M} & \mathrm{M} & \ldots & \mathrm{M} \\
w_{n 1}^{k} & w^{k}{ }_{n 2} & \ldots & w_{n N}^{k}
\end{array}\right]^{T} \\
& n e t^{k}{ }_{i}=x_{i}^{k-1} \cdot w^{k}{ }_{i j}+\theta \\
& x^{k}{ }_{i}=f\left(\text { net }^{k}{ }_{i}\right)
\end{aligned}
$$

$x^{k}{ }_{i}$ is the output of $\mathrm{i}$-th neuron in k-layer, $w_{i j}^{k}$ is the weights from $\mathrm{i}$-th neuron in k-layer to $\mathrm{j}$-th neuron in $\mathrm{k}-1$ layer.

2. Error back propagation:

$$
\begin{gathered}
\mu_{i}^{L}=f^{\prime}\left(\operatorname{net}_{i}^{L}\right) \cdot\left(o_{i}^{L}-x_{i}^{L}\right) \\
U=\left[\mu^{k+1}, \mu_{2}^{k+1}{ }_{2} L \mu^{k+1}{ }_{n}\right] \\
\mu^{k}{ }_{i}=f^{\prime}\left(\text { net }^{k}\right) \cdot U \cdot w^{k+1}{ }_{i j}
\end{gathered}
$$

3. Weight updating:

$$
W_{i j}{ }^{k}(t+1)=W_{i j}{ }^{k}(t)+\eta \mu^{k+1}{ }_{i} x_{j}^{k}
$$

Where, $\eta$ is learning rate, $0<\eta<1$. Input of $\theta$ is 1 .

\section{Constant Power Control based on Neural Network}

Instability of output power of the wind turbine is caused by the randomness of wind speed, the time-varying property of wind turbine parameters and the nonlinearity and time lag of systems ${ }^{[10-12]}$. At this point, adjusting the power output of the wind turbine to maintain constant is essential. The neural network controller of blade pitch angle is designed to regulate stable power output of the wind turbine in this section. 
As is shown in the Fig .2, the structure of neural network controller for blade pitch angle is given, the reference input $P_{a r}$ is reference value of wind turbine power, the error between reference power value $P_{a r}$ of wind turbine and actual power value $P_{a}$ of wind turbine is $e$, which is the input of the neural network controller, and the output of neural network is $\beta_{\text {ref }}$, which is taken as the input of variable pitch servo on the wind power system.

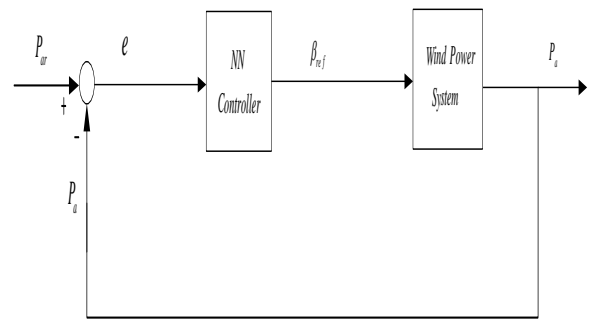

Figure 2. Neural Network Controller for Blade Pitch Angle

\section{SimUlAtion RESUlts}

As is shown in the Fig .3, platform of xilinx system generator for NN controller of DFIG-Based wind turbines is given, the platform include wind module, wind turbine module, neural network module, etc.

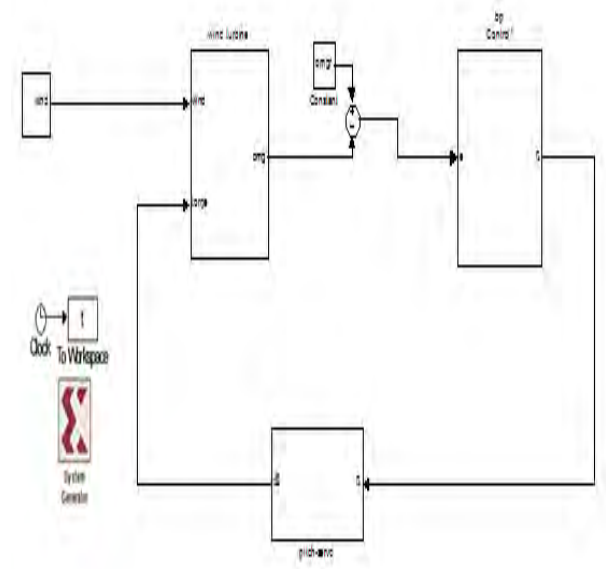

Figure 3. Platform of Xilinx System Generator for NN Controller of DFIG-Based Wind Turbine

As is shown from Fig .4 to Fig .7, we can see that: waveform of the output power of NN control in Fig .7 is more stable than that with PI control in Fig .6; the variable pitch servo has high work efficiency with NN control in Fig .5 than that with PI control in Fig .4.

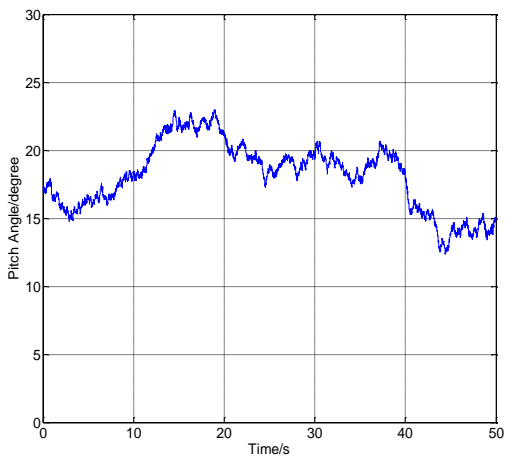

Figure 4. Waveform of the Pitch Angle of PI Control

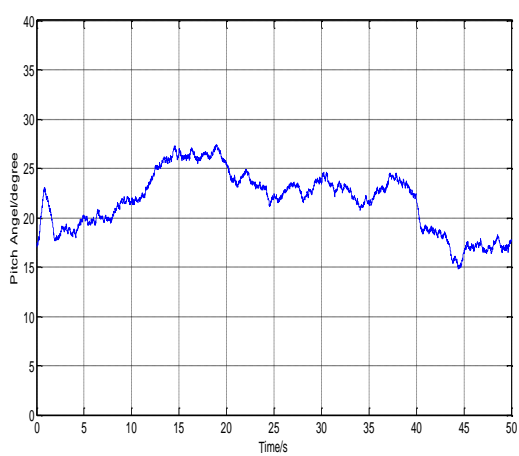

Figure 5. Waveform of the Pitch Angle of NN Control

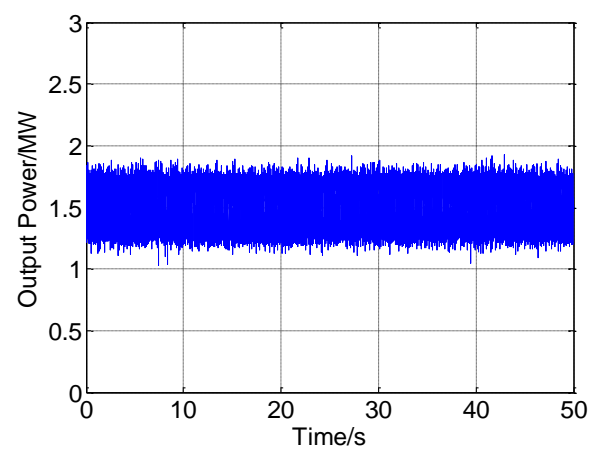

Figure 6. Waveform of the Output Power of PI Control

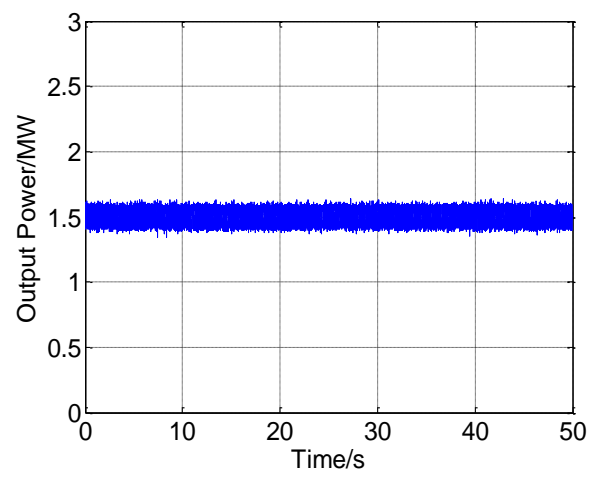

Figure 7. Waveform of the Output Power of NN Control 


\section{CONCLUSION}

In this paper, a new type of neural network control method is designed for variable-pitch wind turbines. Firstly, the model of variable-pitch wind turbines is built up. Secondly, constant power control method based on neural network is designed for the wind turbine, as neural network control methods have strong nonlinear fitting capability, and its reconfigurable learning rules are simple for computers to realize. Finally, the results show that the control method proposed can keep output power more stable, it is a new ideal for the neural network application in the wind power field.

\section{ACKNOWLEDGMENT}

This work has been supported by A Project Funded by the Priority Academic Program Development of Jiangsu Higher Education Institutions (PAPD), A Project Funded by the Dr Foundation of Jiangsu University of Science and Technology under Grant NO.635031303 and A Project Funded by Jiangsu University of Science and Technology under Grant NO. 633031304, A Project Funded by the National Natural Science Fund under Grant NO. 51307074, A Project Funded by the Postdoctoral Key Research Fund of Southeast University under Grant NO.1116000185, A Project Funded by the Postdoctoral Science Foundation of Jiangsu Province under Grant NO.1301005B.

\section{REFERENCES}

[1] M. Kittipong, Y. Chitra, L. Weijen and J.R. Liao, An integration of ANN wind power estimation intounit commitment considering the forecasting uncertainty. IEEE Trans. Ind. Appli., vol. 43, Jun. 2007 pp. 1441-1448.

[2] H. Camblong, I. Martinez de Alegria, M. Rodriguez and G. Abad. Experimental evaluation of windturbines maximum power point tracking controllers. Energ. Convers. Manage., vol. 47, Sept. 2006 pp. 2846-2858.

[3] Z. X. Xing, Q. L. Zheng, and X. J. Yao. PID control in adjustable pitch wind turbine system based on BP neural network. Journal of Shenyang University of Technology. vol. 28, Jun. 2006, pp. 681686

[4] S. Y. Ahmet and O. Zafer. Pitch angle control in wind turbines above the rated wind speed by multi-layer perceptron and radial basis function neural networks. Expert Systems with Applications, vol. 36, Jun. 2009, pp. 9767-9775.

[5] J. Sargolzaei and A. Kianifar. Modeling and simulation of wind turbine Savonius rotors using artificial neural networks for estimation of the power ratio and torque. Simulation Modeling Practice and Theory, vol. 17, Jul. 2009, pp. 1290-1298.

[6] B. Beltran and T. Ahmed-Ali and M. Benbouzid. Sliding Mode Power Control of Variable-Speed Wind Energy Conversion Systems. IEEE Transactions on Energy Conversion, vol. 23, Feb. 2008, pp. 551-558.

[7] S. Bhowmik, R. Spee, and J. H. R. Enslin. Performance optimization for doubly fed wind power generation system. IEEE Transaction on Industry Applications, vol. 35, Apr. 1999, pp. 949958.

[8] A. Gaillard, S. Karimi, P. Poure, S. Saadate, and E. Gholipour. A Fault Tolerant Converter Topology for Wind Energy Conversion System with Doubly Fed Induction Generator. Proc. 2007 European Conference on Power Electronics and Application(EPE 07), IEEE Press, Sept. 2007, pp. 1-6.

[9] S. Karimi, A. Gaillard, P. Poure, and S. Saadate. Current Sensor Fault-Tolerant Control for WECS with DFIG. IEEE Transactions on Industrial Electronics, vol. 56, Nov. 2009, pp. 4660-4670.

[10] M. Bayat, M. Sedighizadeh, and A. Rezazadeh. Wind Energy Conversion Systems Control Using Inverse Neural Model Algorithm[J]. International Journal of Engineering and Applied Sciences, vol. 2, Mar. 2010, pp. 40-46.

[11] Y.D. Song, B. Dhinakaran, and X. Y. Bao. Variable speed control of wind turbines using nonlinear and adaptive algorithms. Journal of Wind Engineering and Industrial Aerodynamics, vol. 85, Dec. 2000, pp. 293-308.

[12] T. Li and Z. C. Ji. Data Driven Control for Wind Energy Conversion System Output Power based on Neural Network Compensator. Journal of Control Science and Engineering, vol.2012, 2012, pp. 1-8 